\title{
PENGARUH BUDAYA ORGANISASI DAN GAYA KEPEMIMPINAN TERHADAP KEPUASAN KERJA PT GLOBAL DIGITAL REPUBLIC DI JAKARTA
}

\author{
Michelle1, Ronnie Resdianto Masman² \\ ${ }^{1}$ Program Studi Manajemen, Fakultas Ekonomi dan Bisnis, Universitas Tarumanagara \\ Email: michellewijaya918@gmail.com \\ ${ }^{2}$ Program Studi Manajemen, Fakultas Ekonomi dan Bisnis, Universitas Tarumanagara* \\ Email: ronniem@fe.untar.ac.id \\ *Penulis Korespondensi
}

\begin{abstract}
ABSTRAK
Tujuan dari penelitian ini adalah untuk mengetahui pengaruh budaya organisasi dan gaya kepemimpinan terhadap kepuasan kerja karyawan PT Global Digital Republic di Jakarta. Populasi pada penelitian ini adalah karyawan yang bekerja pada PT Global Digital Republic, dan terdapat 42 responden dalam penelitian ini. hasil dari penelitian ini menunjukkan bahwa ada pengaruh yang positif antara budaya organisasi dan gaya kepemimpinan terhadap kepuasan kerja karyawan.
\end{abstract}

Kata Kunci: Budaya Organisasi, Gaya Kepemimpinan, Kepuasan Kerja

\section{ABSTRACT}

The purpose of this study was to determine the effect of organizational culture and leadership style on job satisfaction of PT Global Digital Republic employees in Jakarta. The population in this study were employees who worked at PT Global Digital Republic, and the respondents in this study amounted to 42 people. The results of this study indicate that there is a positive influence between organizational culture and leadership style on employee job satisfaction.

Keywords: Organizational Culture, Leadership Style, Job Satisfaction

\section{PENDAHULUAN}

\section{Latar Belakang}

Di era perkembangan yang pesat ini, banyak perusahaan yang saling bersaing untuk mengembangkan bisnisnya. Perusahaan yang sukses adalah perusahaan yang mempunyai orangorang berbakat di bidangnya. Setiap organisasi memiliki departemen manajemen sumber daya manusia yang mengelola segala sesuatu yang berhubungan dengan sumber daya manusia. Keberhasilan atau kegagalan suatu usaha dalam mencapai kinerja yang baik sangat ditentukan oleh pemimpin. Untuk menjalankan bisnis, perusahaan perlu memiliki pemimpin yang kredibel yang dapat mengantisipasi masa depan organisasi dan memanfaatkan peluang untuk perubahan terus-menerus untuk membuka jalan bagi organisasi untuk mencapai tujuannya. Budaya organisasi bertujuan untuk keramahan dan menghubungkan setiap karyawan untuk lebih memahami satu sama lain. Dengan terjalinnya hubungan yang baik antar karyawan, terutama dalam pekerjaan yang berhubungan dengan kerja sama tim, semua karyawan yang terlibat akan merasa puas dengan pekerjaannya karena budaya organisasi tempat mereka bekerja. Oleh karena itu, budaya organisasi yang baik dalam perusahaan membangun hubungan yang baik antara setiap karyawan dan mencapai kepuasan kerja. Setiap individu memiliki tingkat kepuasan yang berbeda-beda tergantung dari nilai-nilai yang berlaku pada dirinya. Kepuasan kerja yang tinggi 
atau rendah dapat memiliki konsekuensi yang tidak setara. Kepuasan kerja yang tinggi terutama didasarkan pada sikap mental orang-orang yang terlibat, karena secara efektif memfasilitasi pencapaian tujuan organisasi. Kepuasan kerja yang buruk merupakan ancaman yang dapat menghancurkan suatu organisasi, tetapi dapat dicapai dengan cepat atau lambat.

PT Global Digital Republic merupakan perusahaan yang bergerak di bidang Business and Digital Marketing seperti jasa pembuatan website, jasa pembuat aplikasi dan jasa SEO dengan customer service. PT Global Indonesia sudah melayani banyak konsumen dengan jasa yang dimilikinya dan semua sesuai dengan kebutuhan konsumen.

\section{Kajian Teori}

Menurut Robbins (terjemahan Wibowo, 2017: 170), kepuasan kerja adalah perilaku yang umum pada suatu pekerjaan, yaitu perbedaan antara jumlah upah yang diterima seorang pekerja dan jumlah bagian imbalan yang ia harapkan untuk diterima. Kepuasan kerja merupakan bagian penting dari pekerjaan seorang individu. Karena setiap pekerja memiliki karakteristik yang berbeda, kepuasan kerja dapat berbeda dan kepuasan kerja dapat memiliki efek yang berbeda. (Bacotic, 2013) mengungkapkan bahwa bahwa kepuasan kerja sering diungkapkan dengan bagaimana karyawan menghargai pekerjaan mereka dan seberapa besar mereka menyukainya. Kepuasan kerja umumnya merupakan interaksi halus antara rekan kerja dan dapat dikatakan positif.

Menurut Wahab dalam Tobari (2016:49) budaya organisasi merupakan suatu sistem nilai, kepercayaan dan kebiasaan dalam suatu organisasi yang saling berinteraksi dengan struktur sistem formalnya untuk menghasilkan norma- norma perilaku organisasi. Menurut Lund (2003, dalam El-Nahas et al., 2013) budaya organisasi adalah nilai dan kepercayaan bersama dalam berinteraksi dengan karyawan serta struktur pada organisasi yang menciptakan norma perilaku. Robbins \& Judge (2013, dalam Triatmanto, 2017) budaya organisasi merupakan sistem makna bersama yang dianut oleh anggota organisasi sebagai pembeda dengan organisasi lainnya.

Menurut Northouse (2015, dalam Alkahtani, 2016) gaya kepemimpinan adalah pendekatan dalam memberikan arahan, mengelola rencana dan memotivasi orang. Lalu Miller, Walker \& Drummond (2002, dalam Al-Sada, Al-Esmael dan Faisal, 2017) menyatakan bahwa gaya kepemimpinan dapat diartikan sebagai pola interaksi antara pemimpin dan bawahan. Avolio et al., (2001, dalam Sedrine et al., 2020) gaya kepemimpinan adalah proses pengaruh sosial yang di mediasi oleh informasi dan teknologi canggih yang menghasilkan perubahan dalam sikap, perasaan, pemikiran, perilaku atau kinerja individu atau kelompok dalam organisasi.

Kerangka pemikiran dalam penelitian ini sebagai berikut:

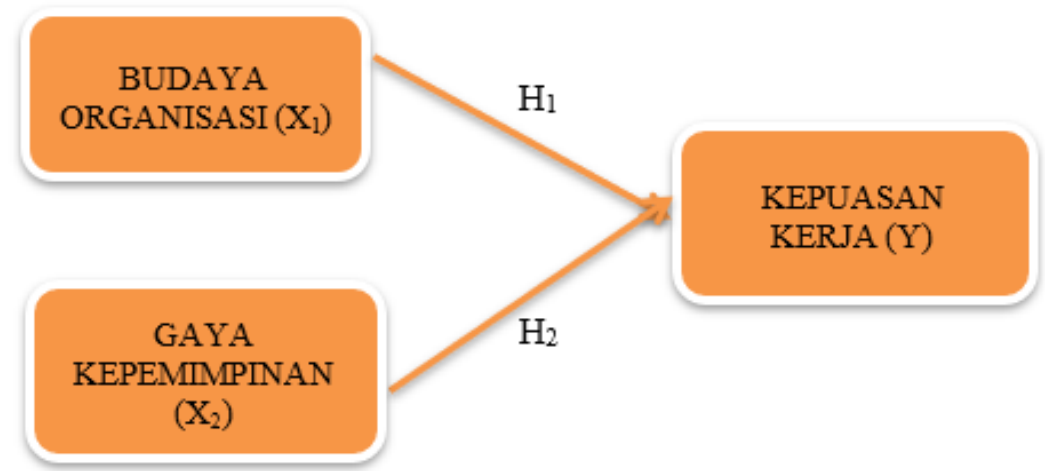

Gambar 1. Kerangka pemikiran 


\section{Hipotesis}

Berdasarkan kajian teori dan kerangka pemikiran, maka hipotesis yang di bentuk adalah: $\mathrm{H}_{1}$ : budaya organisasi memiliki pengaruh terhadap kepuasan kerja karyawan pada PT. Global Digital Republic di Jakarta.

$\mathrm{H}_{2}$ : gaya kepemimpinan memiliki pengaruh terhadap kepuasan kerja karyawan pada PT. Global Digital Republic di Jakarta.

\section{METODE PENELITIAN}

Menurut Sekaran dan Bougie (2013), mengatakan bahwa desain penelitian adalah suatu rencana penelitian secara ilmiah dalam rangka menjawab pertanyaan yang terdapat dalam identifikasi masalah. Penelitian ini dilakukan menggunakan research design kausal. Penelitian kausal digunakan untuk menguji hubungan antara variabel dependen dan variabel independent, yang menurut Sugiyono (2013, h. 3) metode kausal adalah hubungan yang bersifat sebab akibat oleh variabel independen (mempengaruhi) terhadap variabel dependen (dipengaruhi). Dalam penelitian ini populasi dan sampel yang diambil adalah seluruh karyawan pada PT. Artochem Indonesia di Jakarta yang memiliki karyawan sebanyak 42 karyawan. Teknik pengumpulan data dalam penelitian ini menggunakan kuesioner. Aplikasi yang digunakan peneliti dalam penelitian ini adalah SmartPLS versi 3. Uji statistik yang digunakan dalam SmartPLS versi 3 adalah sebagai berikut:

1. Uji Koefisien Determinan (Uji R) yaitu pengujian yang dilakukan apabila R2 semakin besar atau mendekati 1, maka dapat disimpulkan model tersebut semakin tepat. Koefisien determinasi pada regresi linear biasa disebut sebagai seberapa besar kemampuan semua variabel bebas dalam menjelaskan varians dari variabel terikat.

2. Uji Hipotesis yaitu Variabel independen menunjukkan tingkat signifikan apabila nilai t value $\geq 1,96$ pada tingkat alpha $5 \%$. Uji hipotesis juga terkadang disebut dengan konfirmasi analisis data.

3. Uji Goodness of Fit adalah pengujian hipotesis kompatibilitas (goodness of fit) merupakan pengujian hipotesis untuk menentukan apakah suatu himpunan frekuensi yang diharapkan sama dengan frekuensi yang diperoleh dari suatu distribusi, seperti distribusi binomial, normal, atau dari perbandingan lain. Pengujian ini digunakan untuk mengvalidasi performa gabungan antara outer model dan inner model yang memiliki range nilai antara 0-1 dengan interpretasi 0-0,25 (Gof Kecil), 0,25-0,36 (Gof Moderat), dan >36 (Gof Besar).

\section{HASIL DAN PEMBAHASAN}

Dari 42 responden, 22 orang berjenis kelamin perempuan dan 20 orang berjenis kelamin laki-laki. Sebagian besar responden berusia 20 tahun sampai 25 tahun (33 orang, 78.6\%) yang berusia 26 tahun sampai 30 tahun (5 orang, 11.9\%), dan sisanya yang berusia 31 tahun sampai 35 tahun (2 orang, $4.8 \%$ ) dan yang lebih dari 40 tahun (2 orang, $4.8 \%$ ). Pendidikan terakhir sebagian responden adalah S1 (21 orang, 50\%), S2 (4 orang, 9.5\%), D3 (3 orang, 7.1\%) dan sisanya SMA/SMK (14 orang, 33.3\%). Durasi lama bekerja sebagian besar responden adalah kurang dari 1 tahun (19 orang, 45.2\%), 1 tahun sampai 2 tahun (15 orang, 35.7\%), 3 tahun sampai 4 tahun (4 orang, 9.5\%) dan antara 5 tahun sampai 6 tahun (4 orang, $9.5 \%$ ).

Penulis akan membahas tentang hasil pengolahan data dengan software SmartPLS berdasarkan Gambar 2 dan 3. 


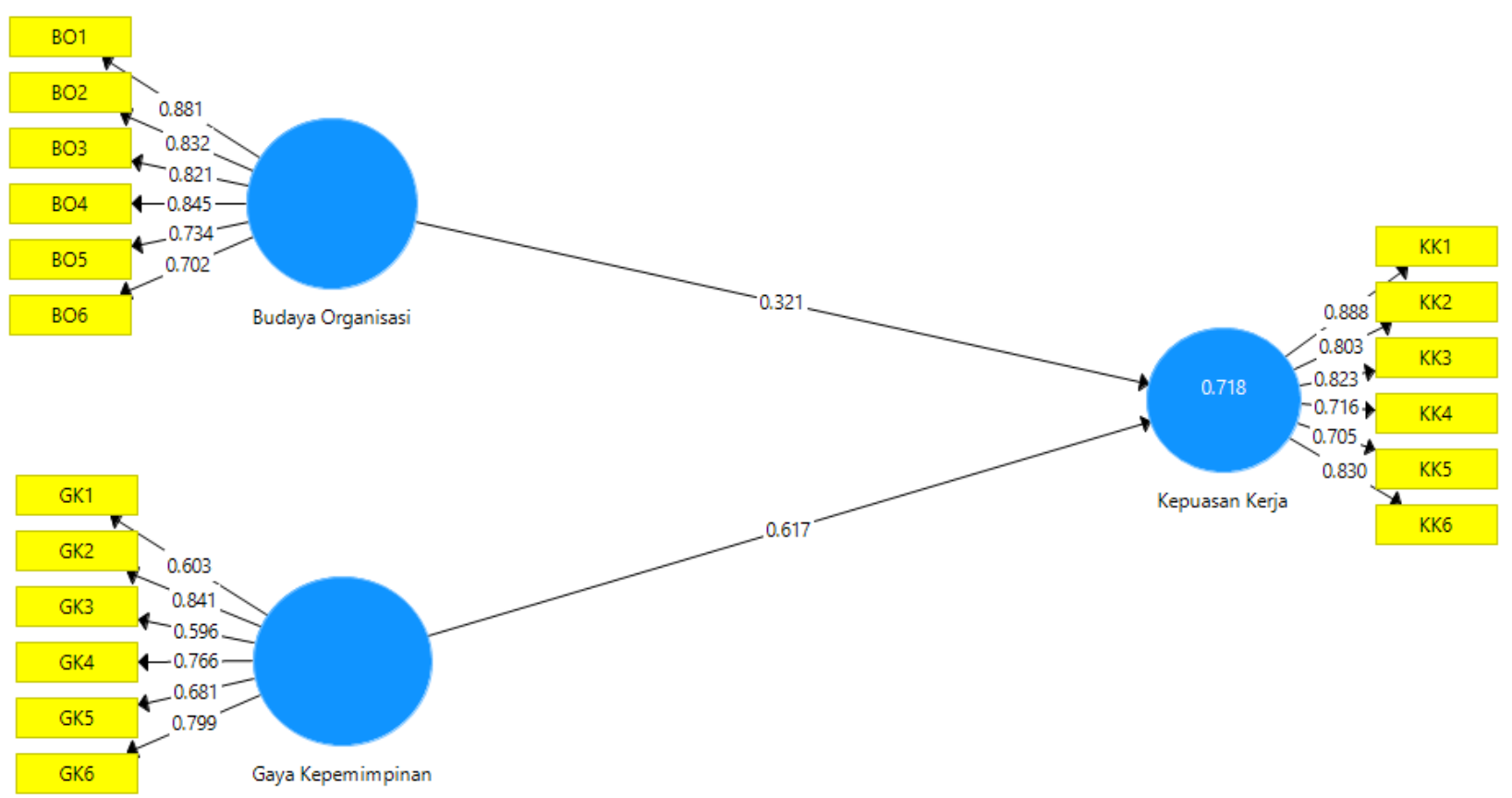

Gambar 2. Hasil Outer loading SmartPLS

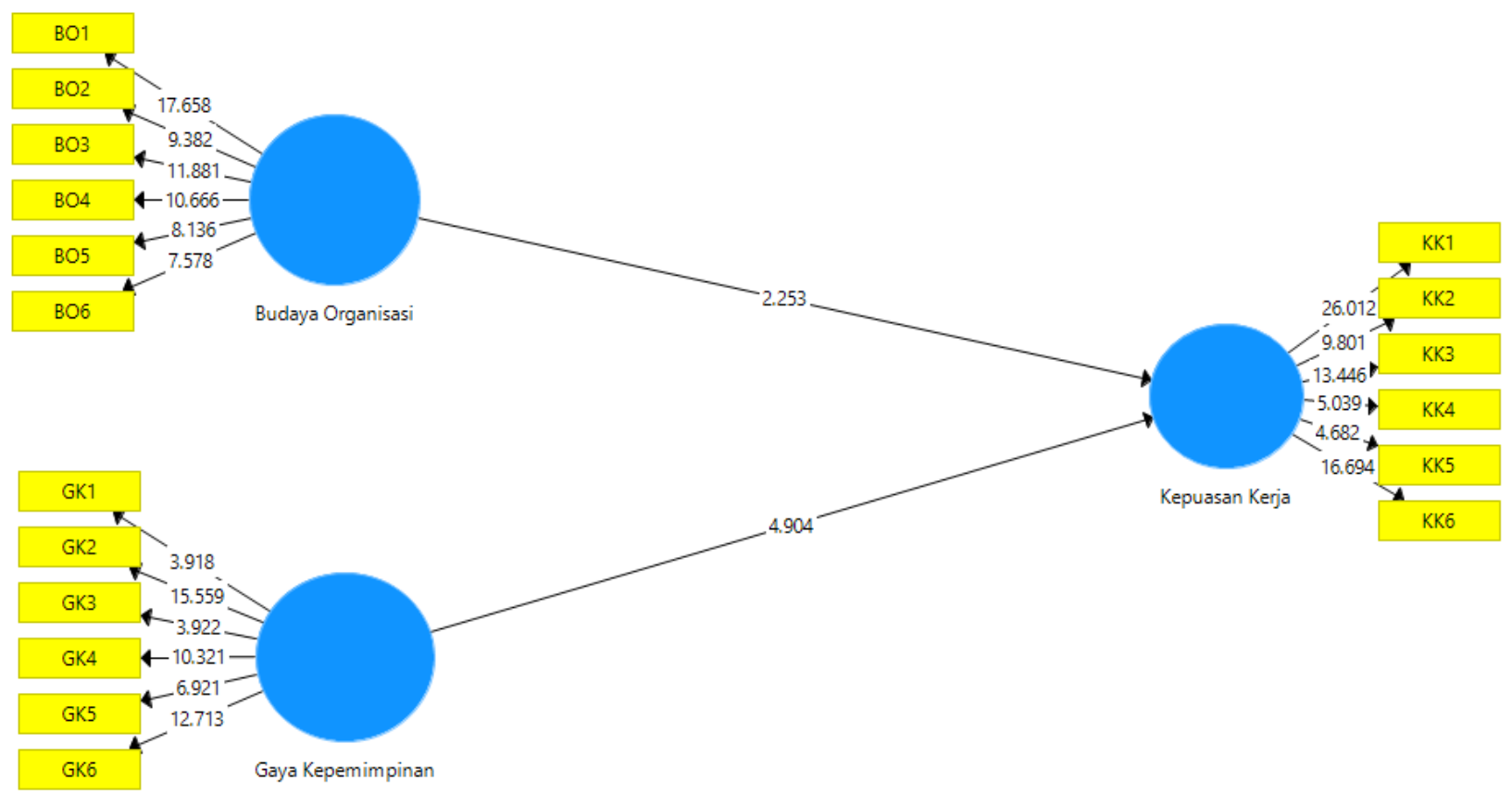

Gambar 3. Hasil uji bootstrapping

\section{Uji Validitas}

Tabel 1. Hasil uji validitas

\begin{tabular}{|c|c|}
\hline Variabel & Average Variance Extracted (AVE) \\
\hline Budaya Organisasi (BO) & 0.648 \\
\hline Gaya Kepemimpinan (GK) & 0.519 \\
\hline Kepuasan Kerja (KK) & 0.635 \\
\hline
\end{tabular}

Nilai AVE dari setiap variabel adalah lebih besar dari 0.5 sehingga dapat ditarik kesimpulan bahwa semua variabel telah memiliki hasil uji validitas yang baik. 


\section{Uji Reliabilitas}

Tabel 2. Hasil uji reliabilitas

\begin{tabular}{|c|c|}
\hline Variabel & Cronbach's Alpha \\
\hline Budaya Organisasi (BO) & 0,891 \\
\hline Gaya Kepemimpinan (GK) & 0,809 \\
\hline Kepuasan Kerja (KK) & 0,884 \\
\hline
\end{tabular}

Nilai Cronbach's alpha untuk tiap variabel adalah lebih besar dari 0,7 sehingga dapat di simpulkan bahwa pernyataan untuk setiap variabel adalah reliable.

\section{Uji Koefisien Determinan $\left(\mathbf{R}^{2}\right)$}

Tabel 3. Hasil uji koefisien determinan

\begin{tabular}{|c|c|c|}
\hline & R-Square & Adjusted R-Square \\
\hline Kepuasan Kerja (Y) & 0.718 & 0.704 \\
\hline
\end{tabular}

Berdasarkan hasil Adjusted $R$-Square $\left(\mathrm{R}^{2}\right)$ pada tabel diatas adalah 0.704 , artinya di mana proporsi budaya organisasi dan gaya kepemimpinan sebesar $70.4 \%$ dan sisanya sebesar $29.6 \%$ dijelaskan pada variabel kepuasan kerja. Sedangkan hubungan kepuasan kerja terhadap budaya organisasi dan gaya kepemimpinan berdasarkan hasil nilai $R$-Square adalah 0.718 yaitu positive dan signifikan bahwa ada hubungan kepuasan kerja terhadap budaya organisasi dan gaya kepemimpinan.

\section{Uji Hipotesis}

Tabel 4. Hasil uji hipotesis

\begin{tabular}{|l|c|c|c|c|c|}
\hline & $\begin{array}{c}\text { Original } \\
\text { Sample (O) }\end{array}$ & $\begin{array}{c}\text { Sampel } \\
\text { Mean }(\mathrm{M})\end{array}$ & $\begin{array}{c}\text { Standard } \\
\text { Deviation }\end{array}$ & t-statistics & $p$-values \\
\hline $\begin{array}{l}\text { Budaya Organisasi (X, }-> \\
\text { Kepuasan Kerja (Y) }\end{array}$ & 0,321 & 0,345 & 0,142 & 2,253 & 0,025 \\
\hline $\begin{array}{l}\text { Gaya Kepemimpinan }\left(\mathrm{X}_{2}\right)-> \\
\text { Kepuasan Kerja (Y) }\end{array}$ & 0,617 & 0,605 & 0,126 & 4,904 & 0,000 \\
\hline
\end{tabular}

a. Dari hasil dari variabel budaya organisasi terhadap kepuasan kerja memiliki jalur koefisien sebesar 0.321 dan T-Statistics sebesar 2.253. T- Statistics yang dihasilkan lebih besar dari 1.96, maka dapat disimpulkan bahwa budaya organisasi memiliki pengaruh positif dan signifikan terhadap kepuasan kerja PT Global Digital Republic di Jakarta.

b. Dari hasil dari variabel gaya kepemimpinan terhadap kepuasan kerja memiliki jalur koefisien sebesar 0.617 dan T- Statistics sebesar 4.904. T- Statistics yang dihasilkan lebih besar dari 1.96, maka dapat disimpulkan bahwa gaya kepemimpinan memiliki pengaruh positif dan signifikan terhadap kepuasan kerja PT Global Digital Republic di Jakarta.

\section{Uji Goodness of Fit}

Tabel 5. Hasil uji Goodness of Fit

\begin{tabular}{|c|c|}
\hline & Sautared Model \\
\hline NFI & $\mathbf{0 . 6 0 4}$ \\
\hline
\end{tabular}

Nilai ini berkisar dari 0-1, nilai NFI yang mendekati 1 menunjukan bahwa model yang diuji memiliki ketepatan yang baik. 


\section{KESIMPULAN DAN SARAN \\ Kesimpulan}

Berdasarkan hasil penelitian yang dilakukan di PT Global Digital Republic yang dilakukan oleh peneliti, maka dapat disimpulkan sebagai berikut :

a. Terdapat pengaruh yang positif dari variabel budaya organisasi terhadap kepuasan kerja PT Global Digital Republic.

b. Terdapat pengaruh yang positif dari variabel gaya kepemimpinan terhadap kepuasan kerja PT Global Digital Republic.

\section{Saran}

Berdasarkan dari hasil penelitian yang telah dilakukan, peneliti akan memberikan beberapa saran atau masukan yang sekiranya dapat digunakan atau bermanfaat bagi perusahaan maupun kepada penelitian selanjutnya, sebagai berikut:

\section{a. Untuk PT Global Digital Republic}

Perusahaan diharapkan bisa tetap mempertahankan budaya organisasi perusahaan untuk menciptakan loyalitas antar karyawan dan pemimpin untuk dapat menciptakan lingkungan kerja yang kondusif berjalan dengan baik dalam jangka waktu yang lama. Kepuasan kerja dipertahankan oleh perusahaan dengan cara memberikan gaya kepemimpinan yang baik serta memberikan motivasi positif kepada para karyawan supaya mereka terus bisa semangat dalam bekerja di perusahaan tersebut. Dalam penelitian yang dilakukan oleh peneliti dengan cara meneliti PT Global Digital Republic mempunyai budaya organisasi dan gaya kepemimpinan yang baik untuk karyawannya. Oleh karna itu, manajemen perusahaan wajib dapat mempertahankan budaya organisasi dan gaya kepemimpinan yang baik untuk karyawan supaya mereka bisa bekerja dengan baik dan juga akan terus berusaha buat tingkatkan kinerja dan kepuasan karyawan demi kemajuan perusahaan kedepannya.

\section{b. Untuk peneliti selanjutnya}

Untuk peneliti selanjutnya diharapkan untuk menambah variabel penelitian lainnya. Karena semakin banyak variabel penelitian maka akan menghasilkan data yang bervariasi, dan indikator yang tepat dengan kondisi perusahaan agar mendapatkan hasil yang diinginkan.

\section{REFERENSI}

Agung, W. K. \& Zarah, P (2016). Metode Penelitian Kuantitatif, Yogyakarta: Pandiva Buku.

Ali, K., \& Agustian, D. W. (2019). Pengaruh Budaya Organisasi Dan Gaya Kepemimpinan terhadap Kepuasan Kerja (Studi Di Rumah Sakit Muhammadiyah Metro). Jurnal Manajemen Magister Darmajaya, 4(02), 186-196.

Ali, K., \& Agustian, D. W. (2019). Pengaruh Budaya Organisasi Dan Gaya Kepemimpinan terhadap Kepuasan Kerja (Studi Di Rumah Sakit Muhammadiyah Metro). Jurnal Manajemen Magister Darmajaya, 4(02), 186-196.

Al-Sada, M., Al-Esmael, B., \& Faisal, M. N. (2017). Influence of organizational culture and leadership style on employee satisfaction, commitment and motivation in the educational sector in Qatar. EuroMed Journal of Business.

Amanda, S. A., \& Masman, R. R. Pengaruh Gaya Kepemimpinan Dan Budaya Organisasi Terhadap Kepuasan Kerja PT. Artochem Indonesia. Jurnal Manajerial Dan Kewirausahaan, 3(3), 832-840.

Bagis, F., Darmawan, A., Hidayah, A., \& Ikhsani, M. M. (2020). The Influence of Leadership Style and Organizational Culture by Mediating Job Satisfaction on Organizational Commitment Case Study in Employees Of Islamic Education Institution. Jurnal Ilmiah Ekonomi Islam, 6(3), 616-620. 
Bangun, W. (2012). Manajemen Sumber Daya Manusia. Jakarta, Indonesia: Erlangga.

Erniwati, S., Ramly, M., \& Alam, R. (2020). Leadership style, organizational culture and job satisfaction at employee performance. Point Of View Research Management, 1(3), 09-18.

Febbyani, A., \& Masman, R. R. (2019). Pengaruh Gaya Kepemimpinan, Kompensasi, Dan Lingkungan Kerja Terhadap Kinerja Karyawan Pada PT. Apatel. Jurnal Manajerial Dan Kewirausahaan, 1(4), 725-735.

Ghozali, I. (2017). Pengaruh Motivasi Kerja, Kepuasan Kerja, dan Kemampuan Kerja Terhadap Kinerja Pegawai Pada Kantor Kementrian Agama Kabupaten Banjar. Jawa Barat: Jurnal Ilmiah Ekonomi Bisnis, Vol 3, No 1, Hal 130 - 137.

Ghozali, Imam. 2014. Structural Equation Modeling, Metode Alternatif dengan Partial Least Square (PLS). Edisi 4. Semarang: Badan Penerbit Universitas Diponegoro.

Gujarati, D. N. (2004). Basic Econometrics, Fourth Edition. Singapore: McGraw-Hill Inc.

Hasibuan S. P. M. (2014). Manajemen Sumber Daya Manusia. Jakarta, Indonesia: Bumi Aksara. Margono, S. (2005). Metode Penelitian Pendidikan, Jakarta: Rineka Cipta, 1997.

Maslow. A. H. (1943). A Theory of Human Motivation. York University, Toronto, Ontario.

McKenna, E. \& Nic, B. (2005). The Essence of Human Resourse Management. UK: Prentice Hall, Inc.

Pawirosumarto, S., Sarjana, P. K., \& Gunawan, R. (2017). The effect of work environment, leadership style, and organizational culture towards job 78 satisfaction and its implication towards employee performance in Parador Hotels and Resorts, Indonesia. International Journal of Law and Management.

Robbins, S. P., \& Coulter, M. (2010). Manajemen Edisi Kesepuluh. Jakarta, Indonesia: Erlangga.

Robbins, S. P., \& Judge, T. A. (2013). Organizational Behavior. London: Pearson Education.

Robbins, S. P., Judge, T. A., \& Langton, N. (2015). Organizational Behaviour: Concepts, Controversies, Applications: Edisi 16. London: Pearson Education.

Robbins, S.P. (2003). Perilaku Organisasi. PT. Indeks Kelompok Gramedia, Jakarta.

Robbins, S.P. and Judge, T.A. (2013), Organizational Behavior, 15 ${ }^{\text {th }} \quad$ ed., Pearson Education, Boston, MA.

Saputra, I. G. A. E., \& Adnyani, I. G. A. D. (2017). Pengaruh Pengaruh Gaya Kepemimpinan dan Budaya Organisasi terhadap Kepuasan Kerja Karyawan. E-Jurnal Manajemen, 6(12), 6592-6619.

Sekaran, U., \& Bougie, R. (2016). Research Methods for Business: A Skill Building Approach Seventh Edition. Chichester, West Sussex, United Kingdom: Wiley.

Sekaran, U., and R. Bougie. (2013). Research Method For Business. Chennai, India: Johan Wiley \& Sons Ltd.

Sekaran, U., and R. Bougie. (2017). Metode Penelitian Bisnis. Edisi 6 \& Buku 2. Salemba Jakarta.

Sulaksono, Ki Hari. Kepemimpinan dan Budaya Organisasi. Edisi 1, Cetakan ke 1. Yogyakarta: Deepublish, Mei 2016.

Waliningsuci, T., Al Musadieq, M., \& Hamid, D. (2019). Pengaruh Budaya Organisasi Dan Gaya Kepemimpinan Terhadap Kepuasan Kerja Dan Kinerja Karyawan. Profit: Jurnal Administrasi Bisnis, 11(1), 1-11.

Wun, M. O., \& Masman, R. R. (2020). Pengaruh Lingkungan Kerja, Penilaian Kinerja, Gaya Kepemimpinan Terhadap Kepuasan Kerja Karyawan FEB Universitas Tarumanagara Di Jakarta. Jurnal Manajerial Dan Kewirausahaan, 2(1), 90-101.

Yukl, Gary. 2015, Leadership in Organizations, Seventh Edition, PT. Indeks, Jakarta. 